\title{
The role of Indigenous knowledges in psychedelic science
}

\author{
EVGENIA FOTIOU* \\ Department of Anthropology, Kent State University, Kent, OH, USA
}

(Received: May 1, 2019; accepted: August 28, 2019)

\begin{abstract}
This paper reflects on potential contributions from anthropology to the field of "psychedelic science." Although the discipline's beginnings went hand in hand with colonialism, it has made significant contributions to the understanding of Indigenous knowledge systems. Furthermore, recent calls to decolonize our theoretical frameworks and methodology, notably the "ontological turn," open up the space for engaging meaningfully with Indigenous worldviews. At this critical juncture of the "psychedelic renaissance," it is important to reflect on whether the current model is satisfactory and on ways to decolonize psychedelic science. What we need is a shift in paradigm, one that will acknowledge the validity of Indigenous worldviews as equal partners to scientific inquiry. Acknowledging the contributions of Indigenous knowledges to psychedelic science is necessary and needs to go hand in hand with attempts to revise biomedical models to be more inclusive in substantial ways. The paper does not argue for the abandonment of the scientific paradigm, rather for the abandonment of its privileged position. Decolonizing psychedelic science will require allowing multiple perspectives to coexist and contribute equally to our efforts going forward.
\end{abstract}

Keywords: decoloniality, Indigenous knowledge systems, psychedelic science, entheogen

\section{INTRODUCTION}

As the psychedelic renaissance is intensifying, we are at a very critical juncture. We can either continue business as usual and perpetuate the hegemony of western science over other ways of knowledge, or step back and reevaluate our frameworks and methodologies to allow for multiple perspectives to contribute to our research. I argue that this is a double imperative; first it is political (Santos, 2014), as it will disrupt the legacies of colonialism and the systematic oppression of Indigenous peoples and second, it might just broaden our lens in ways that will enhance our research efforts. I join multiple scholars who have been arguing for decolonizing the academy and focusing on epistemic justice (Dev, 2018; Keet, 2014; Mignolo, 2009; Overing, 2006; Smith, 1999) and others who have pointed out the validity of Traditional Knowledge (Nicholas, 2018, 2019).

Despite statements on social change, western discourse on psychedelics has been individualistic - focusing on personal transformation - and medicalizing. As Feinberg (2018, p. 40) argued, "any attempt to understand the meaning of substance use that relies only an individualist and medicalizing focus on their therapeutic "effects" will miss the point in understanding the social meaning of substances and their circulation." Indeed, the effects of these individualist and medicalizing discourses are at least twofold: on the one hand, they erase the traditions from which these substances were appropriated, rendering native traditions to romantic stereotypes of noble savages, and on the other hand, they cause us to miss important lessons that could potentially transform the way we do science (Fotiou, 2019). Anthropologists also challenge the universality of psychedelic experiences and caution that we might be imposing western concepts on Indigenous traditions (Feinberg, 2018, p. 41). This too contributes to the erasure of Indigenous shamanisms and the accompanying ontologies and epistemologies (Fotiou, 2016).

Psychedelic science encompasses a variety of substances, but I will be focusing on psychedelic plant medicines whose knowledge was passed on to us by Indigenous peoples. Some of the first people who brought back this knowledge were not necessarily supportive of their popularization and integration to western life. When it comes to such plants, what are our obligations as researchers? How do we decolonize psychedelic science? What role can Indigenous knowledge systems play in this endeavor?

\section{THE STORY SO FAR}

Despite western cultures' ambiguous relationship with drugs, certain ideas still inform much of the research being conducted today, especially regarding the therapeutic potential of psychedelics. Even though the recent renaissance seems to be related to the countercultural movements of the 1960s, the "romance" of the West with these substances seems to be much older. The role of psychedelics in human culture is considered by some to be so important that several authors have connected the origin of religion to psychedelics, among them anthropologists Weston La

\footnotetext{
* Corresponding address: Evgenia Fotiou; Department of Anthropology, Kent State University, 750 Hilltop Drive, Rm. 226 Lowry Hall, Kent, OH 44242, USA; Phone: +1 330672 6862; E-mail: evgeniafotiou@gmail.com
}

This is an open-access article distributed under the terms of the Creative Commons Attribution-NonCommercial 4.0 International License, which permits unrestricted use, distribution, and reproduction in any medium for non-commercial purposes, provided the original author and source are credited, a link to the CC License is provided, and changes - if any - are indicated. 
Barre (1970, 1972, 1975) and Peter Furst (1972, 1976). Numerous artists used them as tools for self-exploration and inspiration. Romantic poets Coleridge, Poe, and Shelley investigated their dreams and trance states also using drugs with the intention to probe the far reaches of the mind as an act of resistance to modernity and the industrial revolution (Pinchbeck, 2004). Mind-altering substances also became a way to explore cultural otherness by making direct contact with "primitive" knowledge. For example, Artaud (1976) attempted to recover the sense of the sacred that European culture had lost by participating in peyote rituals in Mexico.

Aldous Huxley might be the most influential figure for psychedelic researchers today. Through the psychedelic experience, he wanted to achieve an overall understanding of the world and believed that psychedelics could help people with fundamental questions about life (Huxley, 1954). He argued that they can provide direct access to a transcendental reality and become a tool for social change (Benjamin, Marcus, Jennings, Eiland, \& Smith, 1996). Walter Benjamin also saw the pursuit of visionary experience as an extension of a rational and intellectual quest and considered consumerism responsible for the loss of ritual in the West - ritual that would facilitate "ecstatic contact with the cosmos" (Huxley, 1954). He argued what many still argue today: the only way to effect social change is to change the relationship of the senses to the world, in other words, change one's perspective.

Early 20th century approaches centered on the idea that these substances ostensibly induced "madness," clinically identifiable, but perceived as having divine origin by "simpleminded" Indigenous communities. This discourse was part of the image of the irrational and childish "savage." The term psychedelic - mind-manifesting - was introduced in 1957 by Humphrey Osmond, who hoped that this new label would liberate "scientific investigation from the enduring influence of the psychotomimetic (madness mimicking) paradigm, which offered limited field application and a definite pejorative bias" (Yensen, 1989, p. 33). In his research with alcoholics, Osmond found that patients felt that psychedelics could shed light on the eternal question of the purpose and meaning of life and observed that the patients who derived greatest benefit were those who reported mystical experiences.

Today, the fact that psychedelics create powerful religious feelings in people cross-culturally is considered unlikely to be coincidental. Winkelman (2000) suggests a "neurophenomenological" framework to approach Altered States of Consciousness (ASCs). He argues that psychedelics do not merely cause temporary "psychoses" or "mere hallucinations" in people but instead work with existing, adaptive mechanisms in the brain for generating ASCs that can be used constructively. Such researchers do not see shamans as maladjusted, but instead as people who use psychedelic plants to fulfill their roles in the community. Today, the term "entheogen" (Ruck, Bigwood, Staples, Ott, \& Wasson, 1979) - meaning "bringing forth the divine within" - is preferred by some and indicates a shift to sacramental use of some of these substances. However, the psychological paradigm tends to dominate discourse, as most westerners will pursue psychedelic plant medicines for psychological healing.

In the 1960s, artists and writers, such as Allen Ginsberg with his poems on LSD, contributed to the increased interest in psychedelics. This interest has had an enormous impact on the native peoples who originally used them. Gordon Wasson, a former banker, who visited Mexico in the 1950s and tried psilocybin mushrooms with Maria Sabina (Wasson, 1957), is responsible for the waves of Western seekers that flooded Oaxaca in the 1960s the effects of which were rather disruptive (Feinberg, 2003). Something similar is happening in Amazonia surrounding ayahuasca today. Wasson himself, even though he was responsible for popularizing mushrooms and effectively changing the history of the area, frowned upon these spiritual pilgrimages (Znamenski, 2007).

Ayahuasca is a particularly interesting case of a psychedelic plant medicine that left its traditional context in the Amazon jungle to spread throughout the world. Any history of the ayahuasca brew will usually mention a lineage of White men who discovered, reported on, or studied it. One of the earliest western encounters was recorded in 1853 by Richard Spruce, a botanist looking for new plants to collect and classify in the Vaupés area in Colombia (Spruce, 1908). Since then, ayahuasca has been reported by several explorers, botanists, and ethnographers (Koch-Grünberg, 1923; Schultes \& Raffauf, 1992; Villavicencio, 1858).

Interest in ayahuasca arose in the 1960s, with several books introducing ayahuasca to popular audiences. William Burroughs, a known heroin-addict, hoped to find in ayahuasca what he did not find in other drugs. He characteristically wrote: "Yagé may be the final fix." Burroughs traveled to South America to try ayahuasca and 7 years later Allen Ginsberg did the same; their correspondence from that period resulted in the Yagé Letters. Burroughs did not find what he was hoping for in ayahuasca or in Peru - he reported "...I had been conned by medicine men" (Burroughs \& Ginsberg, 1963, p. 15) - while Ginsberg's account is closer to a stereotypical first-person account. There was a fundamental difference between researchers like Schultes and Wasson who only had interest in studying psychedelics and people like Burroughs who hoped to integrate them in western cultural and spiritual life (Znamenski, 2007).

Some anthropological studies also raised awareness about ayahuasca most notably Dobkin de Rios (1972), who discussed urban folk ayahuasca uses. Eduardo Luna's work on mestizo ayahuasca use increased knowledge of ayahuasca and made clear that ayahuasca practices were different from other psychedelics (Luna 1984a, 1984b, 1986). Dobkin de Rios (2006) felt responsible for the popularization of ayahuasca and later published a short piece of expressing regret.

Some work has been carried out on native plant classification, although little progress has been made in integrating any of this knowledge into western botanical classifications of ayahuasca, although the argument for this has been made (De Oliveira, Fagg, Labate, \& Oliveira, 2018). Indigenous groups are said to distinguish at least six different botanical sources of ayahuasca (Stafford \& Bigwood, 1992). Schultes and Hofmann reported that South American natives,

often have special names for diverse "kinds" of ayahuasca, although the botanist frequently finds them all representative of the same species. It is usually difficult to understand the aboriginal method of classification: 
some may be age forms; others may come from different parts of the liana; still others may be ecological forms growing under varying conditions of soil, shade, moisture, etc. The natives assert that these "kinds" have a variety of effects, and it is conceivable that they may actually have different chemical compositions. This possibility is one of the least investigated yet most significant aspects in the study of ayahuasca. (Schultes \& Hofmann, 1992, p. 120)

Most scientific research has focused on working out any therapeutic applications of ayahuasca and its constituents as well as its physiological effects (Callaway, Airaksinen, McKenna, Brito, \& Grob, 1994; Callaway et al., 1996, 1999; Labate \& Cavnar, 2014). The need for more research to understand how psychedelics affect cognitive processes has been argued (Riba \& Barbanoj, 2005) and clinical research conducted in Spain at the Autonomous University of Barcelona on healthy volunteers attempted to remedy this. Several psychological studies suggest that "inner," spiritual, or mystical experiences can be scientifically studied and there is a greater effort to determine uses of ayahuasca in western medicine and psychology. Several psychologists approach ayahuasca as a tool to explore the human psyche, despite evidence of Indigenous use that there is much more to the story than this. As Shanon (1997) - a cognitive psychologist - says, "The real puzzles this brew presents pertain, I think, neither to botany nor to culture but rather to the human mind. As such, the study of ayahuasca belongs first and foremost to the domain of psychology, and more specifically cognitive psychology - the discipline investigating the workings of the human mind."

During the past two decades, several small studies have shown that psychedelics such as ketamine and psilocybin can be beneficial in treating mental illness, including depression, obsessive compulsive disorders, and anxiety (Cloud, 2007). Even more recently, rigorous research conducted at Johns Hopkins University has revived the interest in the potential uses of psychedelics, in this case their use in relieving anxiety in terminally ill patients (Tierney, 2010). In addition, there is a lot of interest in using psychedelic plant medicines including ayahuasca and iboga to treat drug addiction. Takiwasi, a unique clinic combining Amazonian medicine and western psychotherapy with a strong Catholic flavor, has been operating in Tarapoto - Peru since 1992 as a non-profit organization and their staff includes doctors, psychologists, empirical ethnobotanists, healers, and several assistant therapists. Similar efforts in Canada were met with legal obstacles (Posner, 2011). Thus, there is a sustained interest in the scientific community since the 1960s for more research with psychedelics, although some researchers like Jeremy Narby (1999) have also argued for the need to integrate Indigenous ways of knowing with western science.

\section{DECOLONIZING PSYCHEDELIC SCIENCE}

In the past decades, science has turned psychedelic plants and fungi into an object of study by standardizing them into capsules and other preparations to control dosage. However, this is far from how these plants are used by humans in different cultural contexts. These interventions not only change the object of study but might also implicitly delegitimize the traditions from which these plants came from (Tupper \& Labate, 2015). Given the climate of prohibition that we live in, most research to date has focused on whether psychedelics can cure some of the most pervasive conditions of our time. I argue that their therapeutic potential has been well established, and we should be entering an era when we can begin asking more complex and nuanced questions while "unsettling colonial logics and institutions" (Bonilla, 2015). A starting point in decolonizing psychedelic science should be to stop approaching Indigenous ethnomedical systems as subjective, symbolic, and constructed, and biomedicine as objective and factual but rather as another ethnomedical system among others with its own culture (Taylor, 2003). We also need to acknowledge the limitations of scientific knowledge. As feminist scholars have pointed out, all knowledge is "situated" - arising from a certain viewpoint - and is intimately connected to power structures (Haraway, 1988). Claiming objectivity and universality obscures the positionality of scientific knowledge (Harding, 1992). We can only start crossing the "abyssal line" in western scientific knowledge (Santos, 2016) by engaging with local ontologies and epistemologies in our research projects, thus approaching cognitive justice (Santos, 2016).

Despite the great number of scientific studies on ayahuasca and other psychedelic plant medicines, the accompanying local knowledge systems are understudied. Certain well-established stereotypes about the spiritual or noble savage still plague much of the western discourse on Indigenous religious and medical systems. For example, discourse about "mother earth" as a pan-Indian belief, which has been exposed as a western scholarly construction (Gill, 1987), contributes to a superficial engagement with Indigenous ontologies and epistemologies. Westerners tend to approach ayahuasca as a psychological tool, while the vast majority of evidence we have on Indigenous use indicates that ayahuasca and accompanying plants are used in very different manners, specifically to modify the body (Fotiou, 2019; Gow, 2013). The separation between physical, emotional, and spiritual is a western artifact and largely absent in Indigenous knowledge systems. Indigenous knowledge systems depend on an empiricist deductive approach as much as science (Hviding, 1996) and in my own research I have found that knowledge about spirits and spiritual matters is experiential and often mediated through the body, which is in turn manipulated using plants.

What other valuable lessons are we missing from Indigenous knowledge systems? A lot has been written about the relationality between humans and nature or other than human persons as well as the lack of the dualisms dominating western epistemologies. Reciprocity with the natural world is based on a principle of "equivalence between humans and non-humans sharing the biosphere" (Descola, 1996, p. 89) and humans are viewed as participating in a wider community of living beings including non-human persons. In Amazonian cosmologies, where humans, animals, and plants are all people (Viveiros de Castro, 1998), plants can be powerful subjects with the ability to influence human society in profound ways. According to the Napo Runa, plants and human relationships rely on a fundamental 
shared humanity (Swanson, 2009, p. 63). Humans can maintain with them "individual relations governed by a code of behavior similar to that which prevails among the Indians themselves" (Descola, 2012, p. 481). More recently, scholars have argued for the importance of interspecies ethnography (Callicott, 2013; Dev, 2018; Kohn, 2013). If we are to attempt to reconceptualize relationships between humans and non-humans as has been argued in recent years (Daly, French, Miller, \& Nic Eoin, 2016), we should actively revalorize non-Eurocentric epistemologies by making them central to our scientific investigations utilizing collaborative ethnographic methodology. This way we can reverse the process that Santos (2014, p. 237) terms "epistemicide" and identifies as a cognitive injustice: an unjustified lack of "equity between different ways of knowing and different forms of knowledge."

In most cultural settings where ayahuasca is used, it is seen as an intentional agent, indeed a "plant teacher" (Luna 1984a), something that cannot easily be reconciled with scientific epistemology without broadening our lens. Questioning the nature of knowledge was part of the scientific enterprise early on (Tupper \& Labate, 2015); why then is it not the case today? The answer may be in cultural context within which science operates, one in which a neoliberal paradigm is taking over all areas of life leaving little space for risk taking in the production of knowledge, and thus be limiting how far our efforts might go.

Another lesson would be honoring experiential modes of learning through the body. According to Michael Uzendoski (2008, p. 19), "to describe ayahuasca as a hallucinogenic or a drug is to invoke Western histories of repressing people and substances. It would be to ignore the visceral role the body plays in experiencing ayahuasca poetry." Despite scientific efforts to standardize psychedelics, ayahuasca and other psychedelic plant medicines confound "the simplistic pharmacological reductionism that some authorities would impose on it, to cast it as essentially a preparation of "hallucinogenic" alkaloids and to attribute any discernable therapeutic effects to these constituent chemicals" (Tupper \& Labate, 2015, p. 4). The more interesting question to ask is what else might be contributing to the healing effect of psychedelic plant medicines - indeed how does healing happen?

A lot of discourse on the therapeutic use of ayahuasca repeats Eliadean tropes of shamanic flight, although much of Amazonian discourse indicates the centrality of the body in native experience (Gow, 2013). For the Napo Runa, drunken states are seen positively, as a means of attaining knowledge (Uzendoski, 2005). McCallum (1996, p. 363) has also stressed the relationship between knowledge and health, showing on the one hand that among the Cashinahua the same substances and experiences that can be transformed into knowledge may also become illness-causing agents, and on the other hand that "illness can be understood as a disturbance in the body's capacity to know." Practices like the dietas, common in ayahuasca shamanism, that numerous westerners participate in recent years are understudied. Although these constitute local technologies of the body (Fotiou, 2019), there is little scientific investigation to illuminate the mechanisms of acquiring knowledge and healing and communicating with plant entities.
When it comes to healing, the notion that a specific treatment should be applied to specific diseases is unique to biomedicine (Moerman, 1979). Healing in other medical systems, including those that use psychedelics, is a more holistic affair. Indigenous rituals involve all the senses through a variety of elements including music, smell, language, and touch to such a degree that it is difficult to isolate the effects of one element versus another. It is more likely that all the elements work together to bring about healing. Scientific approaches tend to isolate alkaloids and although "set and setting" are recognized to be important (Leary, Metzner, \& Alpert, 1964; Rosegrant, 1976), our models tend to medicalize psychedelic plant medicines. It then makes sense to approach healing and efficacy from a non-biomedical perspective when dealing with healing processes that work on multiple levels.

Our current model of the double-blind clinical trial, arising from and serving people of a certain cultural background, cannot begin to scratch the surface of what is possible with psychedelic plants when used in an Indigenous setting. Many scholars have indicated the role of culture in shaping subjective experience (Fotiou, 2010; Pollock, 2016). On the other hand, Indigenous rituals tend to be rich sensorial experiences engaging all the senses (Fotiou, 2012) and by trying to control the sensory experience, we might be limiting it. Healing is a complex process as the placebo effect indicates (Moerman, 1983) and we might get closer to understanding its mechanisms if we widen our lens. The social nature of health and disease has been discussed extensively in the medical anthropology literature; when we universalize western concepts of illness, we are missing crucial pieces of the healing puzzle. A more holistic approach would also mean the recognition that social and structural solutions need to be implemented. Examples from numerous cultures indicate that communal rituals where the community comes together to heal individuals as well as relationships (Katz, 1982; Laderman, 1991). Many of these ceremonies, including the Native American sweat lodge, are based on an ethic of reciprocity and maintaining balance of interrelationship (Garrett et al., 2011; Portman \& Garrett, 2006). Another example is the relationship between language or narration and healing in native cultures (Milne \& Howard, 2000).

A common argument for the current design of scientific protocols - including the insistence to use placebos - is that they can measure efficacy more objectively. However, the meaning of efficacy is not something to be taken for granted. An important distinction that has been made in the literature is the difference between curing and healing (Waldram, 2000). Biomedicine seems to aim for a cure - as in elimination of disease - while many traditional systems seek to heal. What complicates things further is that healing as in alleviation of suffering - can happen without curing a disease, and at least one study on psilocybin with cancer patients demonstrates this (Griffiths et al., 2016). However, what we are seeking with most of the current research on psychedelics seems to be cures for a variety of ailments that biomedicine has failed to "cure," such as depression (Palhano-Fontes et al., 2019). Despite the positive results, such studies of psychedelic plant medicines are still conducted from a biomedical perspective to find solutions to 
biomedically defined diseases. Although it is widely accepted in the literature that the setting is important in obtaining such positive results, we have not made any advances in understanding efficacy from an Indigenous perspective to counteract western biases (Waldram, 2000). It is the job of researchers to educate regulatory bodies on the limitations of our current approaches, if we are to overcome them.

Last but not least, it is important to reflect and find concrete ways that psychedelic plant medicines can be used to benefit and empower the populations from which we appropriated them. They suffer from a variety of issues due to historical and intergenerational trauma (Garrett et al., 2011), while the recent surge in western uses evokes critiques of neo-colonialism. Indigenous peoples are not a-historical others but historical agents here and now. Superficial representations of Indigenous peoples and their knowledge systems only cause further trauma. When using plants that have been previously used by Indigenous peoples, at the very least they should be consulted about respectful ways of using them.

\section{CONCLUSIONS}

The stories we tell are important. The stories about psychedelic science have been dominated by medicalization, stereotypes, and the heroization of the White men who "discovered" psychedelic plant medicines risking the erasure of the people who initially used these substances. The question we faced is "Do we want to perpetuate the erasure of Indigenous peoples and knowledge systems or are we ready to embrace them as equal partners?" The call for papers for this special issue indicates that enough researchers think it is important to not perpetuate oppression and structural violence as we move forward. I do not profess to have all the answers, rather I hope that this contribution will amplify the voices saying that we cannot continue business as usual. Rather we must rework the epistemological foundations of scientific inquiry to ask new questions and serve new goals.

I have argued for the political imperative of acknowledging the value - and validity - of Indigenous knowledge systems. I join others that have approached science as one way of knowledge among others (Santos, 2016) and argue that local epistemologies - including corporeal ways of knowing and related technologies of the body - can enhance our research efforts. One way to bring together different types of knowledge such as western science and shamanic knowledge is intercultural translation (Santos, 2016) with ethnography offering the most significant contribution to this effort. We no longer need to stay on one side of the "abyssal line" in western knowledge that deems everything on the other side of the line as "incomprehensible magical or idolatrous practices" (Santos, 2014, p. 122). The paper does not argue for the abandonment of the scientific paradigm, rather for the abandonment of its privileged position. Decolonizing psychedelic science will require allowing multiple perspectives to coexist and contribute equally to our efforts going forward. Can we go as far as including Indigenous methodologies (Smith, 1999) in psychedelic science?
I have also argued that there are lessons to be learned from Indigenous worldviews that we are missing in the renaissance of psychedelic science. We need to move beyond appropriating and medicalizing substances and techniques from Indigenous cultures to find the deeper lessons that can be learned from Indigenous worldview and praxis. Unlike biomedical approaches, Indigenous approaches challenge the separation of mind and body. Considering that psychedelic plant medicines in their original context address body and mind as inseparable, it makes sense to revise our methodologies accordingly. What can we learn about healing from Indigenous rituals and other technologies? What about the social aspects of health and healing? Most importantly, how can we support the rebuilding of Indigenous communities as they heal from colonial trauma?

I admit that what I argue here is not easy especially because of mistrust due to centuries of exploitation and marginalization. Another scholar has argued that "The greatest fear of Native researchers may be that traditional healing practices, if written down, will be corrupted and commercialised, thus removing traditional healing from the spiritual realm to a mere prescriptive act" (Portman \& Garrett, 2006, p. 467). This is in fact what we have done with many an Indigenous practice. At the very least, we need to treat Indigenous knowledge systems as integrated systems that include a variety of components and not just appropriate those that will serve our purposes.

What I am proposing here requires a fundamental rethinking of our methodologies and approaches and an honest reevaluation of the knowledge already produced in the field. However, I argue that the potential rewards are such that will make this work worth it. What if instead of misrepresenting Indigenous "others" in the guise of science we begin to describe the world using their concepts and eventually reach "cultural humility" - as is argued in another paper in this volume (George, Michaels, Sevelius, \& Williams, 2019) We need to acknowledge how little we know especially when we tread into conceptual territories that native peoples inhabit. Too much is already lost for us to not take up this work immediately. There is much more for us to gain than there is to lose.

Acknowledgements: The author has no financial assistance to acknowledge but would like to thank the editors of this special issue for starting this important conversation. She would like to show her gratitude to the Indigenous peoples who graciously continue working with academics and settler cultures. Finally, she also shows her gratitude to the plants.

Conflict of interest: The author declares no conflict of interest.

\section{REFERENCES}

Artaud, A. (1976). The peyote dance. New York, NY: Farrar, Straus and Giroux.

Benjamin, W., Marcus, P. B., Jennings, M. W., Eiland, H., \& Smith, G. (1996). Selected writings. Cambridge, MA: Belknap Press. 
Bonilla, Y. (2015). Non-sovereign futures: French Caribbean politics in the wake of disenchantment. Chicago, IL: University of Chicago Press.

Burroughs, W. S., \& Ginsberg, A. (1963). The yage letters. San Francisco, CA: City Lights Books.

Callaway, J. C., Airaksinen, M. M., McKenna, D. J., Brito, G. S., \& Grob, C. S. (1994). Platelet serotonin uptake sites increased in drinkers of ayahuasca. Psychopharmacology, 116(3), 385-387. doi:10.1007/BF02245347

Callaway, J. C., McKenna, D. J., Grob, C. S., Brito, G. S., Raymon, L. P., Poland, R. E., Andrade, E. N., Andrade, E. O., \& Mash, D. C. (1999). Pharmacokinetics of Hoasca alkaloids in healthy humans. Journal of Ethnopharmacology, 65(3), 243-256. doi:10.1016/S0378-8741(98)00168-8

Callaway, J. C., Raymon, L. P., Hearn, W. L., McKenna, D. J., Grob, C. S., Brito, G. S., \& Mash, D. C. (1996). Quantitation of $\mathrm{N}, \mathrm{N}$-dimethyltryptamine and harmala alkaloids in human plasma after oral dosing with ayahuasca. Journal of Analytical Toxicology, 20(6), 492-497. doi:10.1093/jat/20.6.492

Callicott, C. (2013). Interspecies communication in the Western Amazon: Music as a form of conversation between plants and people. European Journal of Ecopsychology, 4, 32-43.

Cloud, J. (2007). Was Timothy Leary right? Time, 169(18), 64-65.

Daly, L., French, K., Miller, T. L., \& Nic Eoin, L. (2016). Integrating ontology into ethnobotanical research. Journal of Ethnobiology, 36(1), 1-9. doi:10.2993/0278-0771-36.1.1

De Oliveira, R. C., Fagg, C. W., Labate, B. C., \& Oliveira, J. S. (2018, September 27). The urgent need to review the botanical classification of the ayahuasca vine. Retrieved July 7, 2019, from https://chacruna.net/urgent-botanical-classification-ayahuasca/

Descola, P. (1996). Constructing natures: Symbolic ecology and social practice. In G. Pálsson \& P. Descola (Eds.), Nature and society: Anthropological perspectives (pp. 82-102). London, UK/New York, NY: Routledge.

Descola, P. (2012). Beyond nature and culture: The traffic of souls. Journal of Ethnographic Theory, 2(1), 473-500. doi:10.14318/ hau2.1.021

Dev, L. (2018). Plant knowledges: Indigenous approaches and interspecies listening toward decolonizing ayahuasca research. In B. C. Labate \& C. Cavnar (Eds.), Plant medicines, healing and psychedelic science (pp. 185-204). Cham, Switzerland: Springer.

Dobkin de Rios, M. (1972). Visionary vine: Hallucinogenic healing in the Peruvian Amazon. Prospect Heights, IL: Waveland Press.

Dobkin de Rios, M. (2006). Mea culpa: Drug tourism and the anthropologist's responsibility. Anthropology News, 47(7), 20. doi:10.1525/an.2006.47.7.20

Feinberg, B. (2003). The Devil's book of culture: History, mushrooms, and caves in Southern Mexico. Austin, TX: University of Texas Press.

Feinberg, B. (2018). Undiscovering the Pueblo Mágico: Lessons from Huautla for the Psychedelic Renaissance. In B. C. Labate \& C. Cavnar (Eds.), Plant medicines, healing and psychedelic science (pp. 37-54). Cham, Switzerland: Springer.

Fotiou, E. (2010). Encounters with sorcery: An ethnographer's account. Anthropology and Humanism, 35(2), 192-203. doi:10.1111/j.1548-1409.2010.01066.x

Fotiou, E. (2012). Working with "La Medicina": Elements of healing in contemporary ayahuasca rituals. Anthropology of
Consciousness, 23(1), 6-27. doi:10.1111/j.1556-3537.2012. 01054.x

Fotiou, E. (2016). The globalization of ayahuasca shamanism and the erasure of Indigenous shamanism. Anthropology of Consciousness, 27(2), 151-179. doi:10.1111/anoc.12056

Fotiou, E. (2019). Technologies of the body in contemporary Amazonian Shamanism: Implications for future research. $\mathrm{Hu}$ man Ecology, 47(1), 145-151. doi:10.1007/s10745-018-0043-6

Furst, P. T. (1972). Flesh of the Gods: The ritual use of hallucinogens. New York, NY: Praeger Publishers.

Furst, P. T. (1976). Hallucinogens and culture. San Francisco, CA: Chandler \& Sharp.

Garrett, M. T., Torres-Rivera, E., Brubaker, M., Portman, T. A. A., Brotherton, D., West-Olatunji, C., Conwill, W., \& Grayshield, L. (2011). Crying for a vision: The Native American sweat lodge ceremony as therapeutic intervention. Journal of Counseling \& Development, 89(3), 318-325. doi:10.1002/ j.1556-6678.2011.tb00096.x

George, J. R., Michaels, T. I., Sevelius, J., \& Williams, M. T. (2019). The psychedelic renaissance and the limitations of a White-dominant medical framework: A call for indigenous and minority inclusion. Journal of Psychedelic Studies. doi:10.1556/2054.2019.015

Gill, S. D. (1987). Mother Earth: An American story. Chicago, IL: University of Chicago Press.

Gow, P. (2013). DormidoBorrachoAlucinando: EstadosCorporalesAlterados a Través de la Ayahuasca en la Amazonia Peruana [Asleep, drunk, hallucinating: Altered body states through ayahuasca in the Peruvian Amazon]. In B. C. Labate \& J. C. Bouso (Eds.), Ayahuasca y Salud (pp. 66-87). Barcelona, Spain: La Liebre de Marzo.

Griffiths, R. R., Johnson, M. W., Carducci, M. A., Umbricht, A., Richards, W. A., Richards, B. D., Cosimano, M. P., \& Klinedinst, M. A. (2016). Psilocybin produces substantial and sustained decreases in depression and anxiety in patients with life-threatening cancer: A randomized double-blind trial. Journal of Psychopharmacology (Oxford, England), 30(12), 1181-1197. doi:10.1177/0269881116675513

Haraway, D. (1988). Situated knowledges: The science question in feminism and the privilege of partial perspective. Feminist Studies, 14(3), 575-599. doi:10.2307/3178066

Harding, S. (1992). Rethinking standpoint epistemology: What is "strong objectivity"? The Centennial Review, 36(3), $437-470$.

Huxley, A. (1954). The doors of perception. New York, NY: Harper.

Hviding, E. (1996). Nature, culture, magic, science: On metalanguages for comparison in cultural ecology. In P. Descola \& G. Pálsson (Eds.), Nature and society: Anthropological perspectives (pp. 165-184). London, UK/New York, NY: Routledge.

Katz, R. (1982). Boiling energy: Community healing among the Kalahari Kung. Cambridge, MA: Harvard University Press.

Keet, A. (2014). Epistemic 'Othering' and the decolonisation of knowledge. Africa Insight, 44(1), 23-37.

Koch-Grünberg, T. (1923). Zwei Jahre bei den Indianern Nordwest-Brasiliens [Two years with the Indians of northwest Brazil]. Stuttgart, Germany: Strecker und Schröder.

Kohn, E. (2013). How forests think: Toward an anthropology beyond the human. Berkekey, CA: University of California Press. 
La Barre, W. (1970). Old and new world narcotics: A statistical question and an ethnological reply. Economic Botany, 24(1), 73-80. doi:10.1007/BF02860640

La Barre, W. (1972). Hallucinogens and the shamanic origins of religion. In P. Furst (Ed.), Flesh of the Gods: The ritual use of hallucinogens (pp. 261-278). New York, NY: Praeger Publishers.

La Barre, W. (1975). The peyote cult. Hamden, TN: Archon Books.

Labate, B. C., \& Cavnar, C. (Eds.). (2014). The therapeutic use of ayahuasca. Berlin, Germany/New York, NY: Springer.

Laderman, C. (1991). Taming the wind of desire: Psychology, medicine, and aesthetics in Malay shamanistic performance. Berkeley, CA: University of California Press.

Leary, T., Metzner, R., \& Alpert, R. (1964). The psychedelic experience: A manual based on the Tibetan Book of the Dead. Sacaucus, NJ: Citadel Press.

Luna, L. E. (1984a). The concept of plants as teachers among four mestizo shamans of Iquitos, Northeastern Peru. Journal of Ethnopharmacology, 11(2), 135-156. doi:10.1016/03788741(84)90036-9

Luna, L. E. (1984b). The healing practices of a Peruvian shaman. Journal of Ethnopharmacology, 11(2), 123-133. doi:10.1016/ 0378-8741(84)90035-7

Luna, L. E. (1986). Vegetalismo: Shamanism among the Mestizo population of the Peruvian Amazon. Stockholm, Sweden: Almqvist \& Wiksell International.

McCallum, C. (1996). The body that knows: From Cashinahua epistemology to a medical anthropology of lowland South America. Medical Anthropology Quarterly, 10(3), 347-372. doi:10.1525/maq.1996.10.3.02a00030

Mignolo, W. (2009). Epistemic disobedience, independent thought and decolonial freedom. Theory, Culture and Society, 26(7-8), 159-181. doi:10.1177/0263276409349275

Milne, D., \& Howard, W. (2000). Rethinking the role of diagnosis in Navajo religious healing. Medical Anthropology Quarterly, 14(4), 543-570. doi:10.1525/maq.2000.14.4.543

Moerman, D. E. (1979). Anthropology of symbolic healing. Current Anthropology, 20(1), 59-80. doi:10.1086/202203

Moerman, D. E. (1983). Physiology and symbols: The anthropological implications of the placebo effect. In L. Romanucci-Ross, D. E. Moerman, \& L. R. Tancredi (Eds.), The anthropology of medicine: From culture to method (pp. 156-171). New York, NY: Praeger.

Narby, J. (1999). The cosmic serpent: DNA and the origins of knowledge. New York, NY: Jeremy P. Tarcher/Putnam.

Nicholas, G. (2018, February 21). When scientists "Discover" what Indigenous people have known for centuries. Retrieved April 29, 2019, from https://www.smithsonianmag.com/ science-nature/why-science-takes-so-long-catch-up-traditionalknowledge-180968216/

Nicholas, G. (2019, February 22). An uneasy alliance: Indigenous traditional knowledge enriches western science. Retrieved February 22, 2019, from https://intercontinentalcry.org/ an-uneasy-alliance-indigenous-traditional-knowledge-enricheswestern-science/

Overing, J. (2006). The backlash to decolonizing intellectuality. Anthropology and Humanism, 31(1), 11-40. doi:10.1525/ahu. 2006.31.1.11

Palhano-Fontes, F., Barreto, D., Onias, H., Andrade, K. C., Novaes, M. M., Pessoa, J. A., Mota-Rolim, S. A., Osório, F. L., Sanches, R., Dos Santos, R. G., Tófoli, L. F., de Oliveira Silveira, G.,
Yonamine, M., Riba, J., Santos, F. R., Silva-Junior, A. A., Alchieri, J. C., Galvão-Coelho, N. L., Lobão-Soares, B., Hallak, J. E. C., Arcoverde, E., Maia-de-Oliveira, J. P., \& Araújo, D. B. (2019). Rapid antidepressant effects of the psychedelic ayahuasca in treatment-resistant depression: A randomized placebocontrolled trial. Psychological Medicine, 49(4), 655-663. doi:10.1017/S0033291718001356

Pinchbeck, D. (2004). Breaking open the head: A visionary journey from cynicism to shamanism. London: Flamingo.

Pollock, D. (2016). Drugged subjectivity, intoxicating alterity. Anthropology of Consciousness, 27(1), 28-50. doi:10.1111/ anoc. 12050

Portman, T., \& Garrett, M. (2006). Native American healing traditions. International Journal of Disability, Development and Education, 53(4), 453-469. doi:10.1080/103491206010 08647

Posner, M. (2011, November 9). B.C. doctor agrees to stop using Amazonian plant to treat addictions. The Globe and Mail. Retrieved from https://www.theglobeandmail.com/life/healthand-fitness/bc-doctor-agrees-to-stop-using-amazonian-plantto-treat-addictions/article4250579/

Riba, J., \& Barbanoj, M. J. (2005). Bringing ayahuasca to the clinical research laboratory. Journal of Psychedelic Drugs, 37(2), 219-230. doi:10.1080/02791072.2005.10399804

Rosegrant, J. (1976). The impact of set and setting on religious experience in nature. Journal for the Scientific Study of Religion, 15(4), 301-310. doi:10.2307/1385633

Ruck, C. A., Bigwood, J., Staples, D., Ott, J., \& Wasson, R. G. (1979). Entheogens. Journal of Psychedelic Drugs, 11(1-2), 145-146. doi:10.1080/02791072.1979.10472098

Santos, B. de S. (2014). Epistemologies of the South: Justice against epistemicide. Boulder, $\mathrm{CO} /$ London, UK: Paradigm Publishers.

Santos, B. de S. (2016). Epistemologies of the South and the future. From the European South, 1, 17-29.

Schultes, R. E., \& Hofmann, A. (1992). Plants of the gods: Their sacred, healing, and hallucinogenic powers. Rochester, VT: Healing Arts Press.

Schultes, R. E., \& Raffauf, R. F. (1992). Vine of the soul: Medicine men, their plants and rituals in the Colombian Amazonia. Oracle, AZ: Synergetic Press.

Shanon, B. (1997). Cognitive psychology and the study of ayahuasca. Jahrbuch Für Ethnomedizin Und Bewusstseinsforschung/Yearbook for Ethnomedicine and the Study of Consciousness, 6, 77-94.

Smith, L. T. (1999). Decolonizing methodologies: Research and Indigenous peoples. London, UK: Zed.

Spruce, R. (1908). Notes of a botanist on the Amazon \& Andes: Being records of travel on the Amazon and its tributaries, the Trombetas, Rio Negro, Uaupés, Casiquiri, Pacimoni, Huallaga, and Pastasa; as also to the Cataracts of the Orinoco, along the Eastern Side of the Andes of Peru and Ecuador, and the shores of the Pacific, during the years 1849-1864. London, UK: Macmillan.

Stafford, P. G., \& Bigwood, J. (1992). Psychedelics encyclopedia. Berkekey, CA: Ronin Pub.

Swanson, T. (2009). Singing to Estranged lovers: Runa relations to plants in the Ecuadorian Amazon. Journal for the Study of Religion, Nature and Culture, 3(1), 36-65. doi:10.1558/ jsrnc.v3i1.36

Taylor, J. S. (2003). Confronting "culture" in medicine's "culture of no culture." Academic Medicine: Journal of the Association 
of American Medical Colleges, 78(6), 555-559. doi:10.1097/ 00001888-200306000-00003

Tierney, J. (2010). Hallucinogens have doctors tuning in again. The New York Times. Retrieved from http://www.nytimes.com/ 2010/04/12/science/12psychedelics.html

Tupper, K., \& Labate, B. (2015). Ayahuasca, psychedelic studies and health sciences: The politics of knowledge and inquiry into an Amazonian plant brew. Current Drug Abuse Reviews, 7(2), 71-80. doi:10.2174/187447370866 6150107155042

Uzendoski, M. (2005). The Napo Runa of Amazonian Ecuador. Urbana, Champaign: University of Illinois Press.

Uzendoski, M. (2008). Somatic poetry in Amazonian Ecuador. Anthropology and Humanism, 33(1/2), 12-29. doi:10.1111/ j.1548-1409.2008.00002.x

Villavicencio, M. (1858). Geografía de la república del Ecuador [Geography of the Republic of Ecuador]. New York, NY: Impr. de R. Craighead.
Viveiros de Castro, E. (1998). Cosmological deixis and Amerindian perspectivism. The Journal of the Royal Anthropological Institute, 4(3), 469-488. doi:10.2307/3034157

Waldram, J. B. (2000). The efficacy of traditional medicine: Current theoretical and methodological issues. Medical Anthropology Quarterly, 14(4), 603-625. doi:10.1525/maq.2000. 14.4.603

Wasson, G. (1957). Seeking the magic mushroom. Life, 100-120.

Winkelman, M. J. (2000). Shamanism: The neural ecology of consciousness and healing. Greenwich, England: Greenwood Publishing Group.

Yensen, R. (1989). From mysteries to paradigms: Humanity's journey from sacred plants to psychedelic drugs. In C. Ratsch (Ed.), Gateway to inner space (pp. 11-53). Bridport, UK/ Garden City Park, NY: Prism Press.

Znamenski, A. A. (2007). The beauty of the primitive: Shamanism and western imagination. Oxford, UK/New York, NY: Oxford University Press. 